\title{
PHOTO-BASED 3D SCANNING VS. LASER SCANNING - COMPETITIVE DATA ACQUISITION METHODS FOR DIGITAL TERRAIN MODELLING OF STEEP MOUNTAIN SLOPES
}

\author{
N. Kolecka ${ }^{\text {a }}$ \\ ${ }^{a}$ Department of GIS, Cartography and Remote Sensing, Jagiellonian University, Krakow, Poland - \\ nkolecka@gis.geo.uj.edu.pl
}

Commission VI, WG I/4, III/4, IV/2, VII/2

KEY WORDS: Photogrammetry, TLS, DEM/DTM, Comparison, Visualization, Three-dimensional, Model

\begin{abstract}
:
The paper presents how terrestrial laser scanning (TLS) and terrestrial digital photogrammetry were used to create a 3D model of a steep mountain wall. Terrestrial methods of data acquisition are the most suitable for such relief, as the most effective registration is perpendicular to the surface. First, various aspects of photo-based scanning and laser scanning were discussed. The general overview of both technologies was followed by the description of a case study of the western wall of the Kościelec Mountain $(2155 \mathrm{~m})$. The case study area is one of the most interesting and popular rock climbing areas in the Polish High Tatra Mts. The wall is about 300 meters high, has varied relief and some parts are overhung. Triangular irregular mesh was chosen to represent the true3D surface with its complicated relief. To achieve a more smooth result for visualization NURBS curves and surfaces were utilized. Both 3D models were then compared to the standard DTM of the Tatra Mountains in TIN format, obtained from aerial photographs ( $0.2 \mathrm{~m}$ ground pixel size). The results showed that both TLS and terrestrial photogrammetry had similar accuracy and level of detail and could effectively supplement very high resolution DTMs of the mountain areas.
\end{abstract}

\section{INTRODUCTION}

Many applications rely on accurate digital terrain models. Suitable data are needed to create such models. Depending on a purpose of the digital representation and a size of the object, the data must meet various requirements, like sufficient speed of acquisition, acceptable cost and high accuracy. Since the middle of the $20^{\text {th }}$ century, when photogrammetry began to be used widely, new technologies of relief measurement have appeared. Laser scanning was introduced to the research community in the early 1990s, and the first terrestrial laser scanner was constructed in 1999. High speed and accuracy of data acquisition, as well as the eagerness to keep abreast of technological progress, directed the main interest to this new technology. However, image-based methods have also progressed recently, especially in the field of information extraction from digital images. Many automatic algorithms were implemented into professional software, which improved and accelerated image processing. A significant improvement in high-quality $3 \mathrm{D}$ model creation is photo-based $3 \mathrm{D}$ scanning, known also as dense stereo matching. This technology, producing a dense point cloud, originates in photogrammetric approaches to Digital Terrain Models (DTM) and computer vision stereo matching. Both technologies are range, noninvasive and prevent people from entering the zone surrounding the slope, often related to a serious danger. At the same time they provide digital documentation and give a great potential for realistic and interactive visualization (Table 1).

Steep mountain slopes are the subject of interest in various fields, such as tourism, engineering or geomorphology. These areas suffer from such hazardous events as rock and snow falls or landslides and demand constant monitoring. On the other hand they are also a part of the landscape utilized by hikers and climbers, who hunger for detailed rock representation instead of plain images or drawings. The 3D modelling can be very efficient and useful when it comes to monitoring, interpretation and analysis of steep mountain slopes. There are many examples of individual and combined applications of the 3D modelling technologies (Table 1).

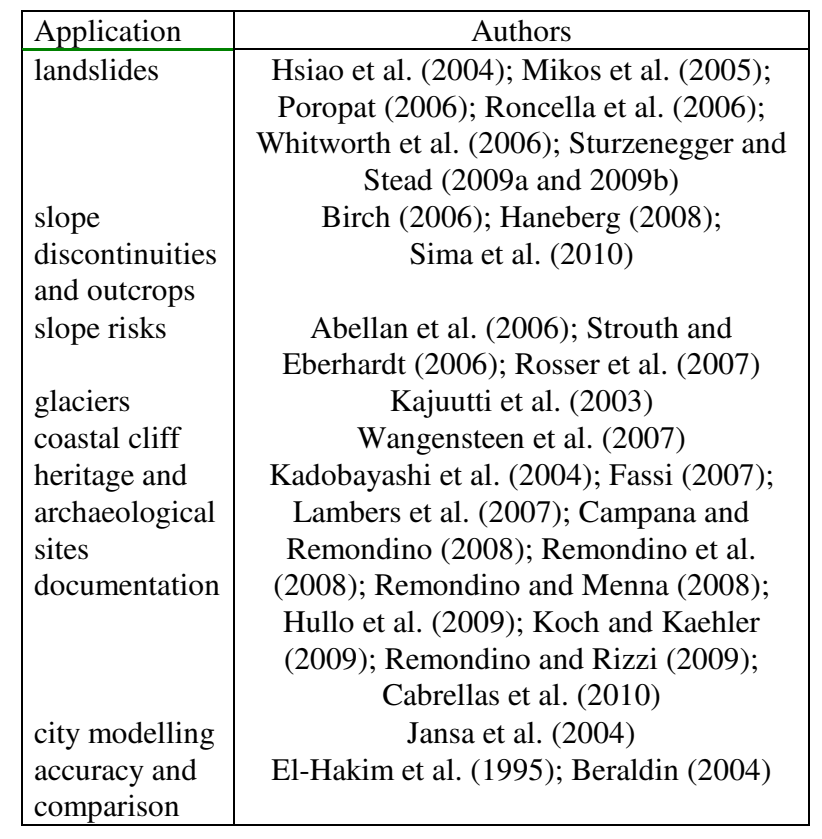

Table 1. Overview of applications of terrestrial laser scanning and terrestrial photogrammetry 
The main goal of this paper is to investigate $3 \mathrm{D}$ models developed with photo-based and laser scanning data, with regard to their accuracy, resemblance and conformity, as well as their usefulness for steep mountain slopes modelling.

\section{REVIEW OF TECHNOLOGY}

This section gives an overview of three different solutions in data acquisition for terrain modelling, paying attention to their individual features and their complementarity. Only terrestrial sensors are taken into consideration.

\subsection{Terrestrial photogrammetry}

Photogrammetry allows to determine the geometric properties of objects and metrically reconstruct them in $3 \mathrm{D}$ or $2 \mathrm{D}$ by means of measuring and interpreting photographic images, using Image-based Modelling (IBM; Remondino and El-Hakim, 2006). In terms of camera position, terrestrial photogrammetry refers to measurements from a fixed terrestrial location (Luhmann et al., 2006).

Fundamental geometrical model is based on reconstructing bundles of rays, defined for each camera by perspective centre and each image point, showing spatial direction to the corresponding object point. If at least two spatially separated images with known 3D camera orientation are available, than it is possible to determine object coordinates of image point by means of corresponding (homologous) rays. Apart from metric information, photographs provide also colours, required to build a fully textured 3D model.

Nowadays, high resolution digital cameras are relatively inexpensive, off-the-shelf equipment. They are portable and lightweight, enabling to take easily a large number of photographs and to record different objects. Depending on the degree of digital system automation, even non-specialist operators are able to carry out the processing cycle and deliver spatial information. Some limitations, however, are lack of fully automatic procedures that provide satisfactory results (especially in textureless parts of pictures, where no trustworthy point cloud can be generated) and stereoscopic measurements that require experienced operator. Calibration can be done easily on a testfield or on the job (self-calibration) to provide more accurate measurements. However, to solve spatial intersection, space resection or to reconstruct 3D bundle, exterior (describing position and orientation of the camera in the global system) and interior (focal length, coordinates of principal point and distortion parameters) orientation parameters are required. The relationship between object and image coordinates of a point are described as functions of the interior and exterior parameters of one image by collinearity equations (Luhmann et al., 2006; Kraus, 2007; Lerma et al., 2010).

\subsection{Terrestrial Laser Scanning}

Laser scanning is a technique enabling dense surface or object sampling to provide a point cloud, i.e. a large quantity of 3D point coordinates, describing the object. Remondino and ElHakim (2006) refer to this technique as Range-based Modelling (RBM). Many scanning devices register intensity values, i.e. strength of the returned laser pulse, which depends on the material of the surface, with respect to the optical wavelength. Also many of them are equipped with a separately mounted or internal digital camera, which provides RGB values of surrounding objects. Terrestrial laser scanning (TLS) operates from the ground and generates data in local coordinate system. It can be classified referring to the possible range of measurements or the principle of the device operation (triangulation, time-of-flight and phase-based).

For the topographic mapping the time-of-flight based scanners are in common use (Buckley et al., 2008). The device measures the return time of each emitted laser pulse and converts it into a range value. Together with the angular components that allows $3 \mathrm{D}$ coordinates to be calculated, in the same way as while a total station survey. The main difference, however, is that commercial laser scanners can survey even hundreds of thousands of 3D points per second. Such a large, multi-gigabyte data sets are a great challenge in terms of manipulation, interpretation and management. While the great point density increases the final model accuracy, it also consumes more time during data acquisition (Bellian et al., 2005) which is crucial for rapid accidents registration.

High prices limit currently the accessibility of TLS. The other limitation is their heavy weight. This may cause serious transportation problems in the field, especially in remote areas or when a complex object is being surveyed and many scanner locations are necessary to avoid occlusions. For all those reasons it is important to carefully plan the fieldwork beforehand (Lerma Garcia et al., 2008).

\subsection{Integrated TLS and terrestrial photogrammetry}

It is widely known, that potential benefits and limitations of both technologies are complementing one another. Jansa et al. (2004) provide a comparison of dissimilar sensors characteristics to confirm this general truth. Remondino et al. (2005) state that combination of both methods yielded good results, with 3D models being more accurate and easier to represent complex objects. Image-based approach is recommended to obtain a higher geometric accuracy, while TLS perfectly satisfies demand for a high level of detail. Roennholm et al. (2007) present four different levels of integration that emphasize features of the input data, recommending to select one of them with respect to the desired end-product. Combination of two techniques is recommended especially when the study area is large and complex or in case of varying nature of the object (Lerma et al., 2010).

\subsection{Surface reconstruction}

Generation of DTMs has become mature with respect to methodology and algorithms, but this statement does not apply to very steep slopes. In such a case, as a result of the photobased or laser scanning data acquisition, we receive unorganized point clouds, which are often incomplete, noisy and / or sparse. Free form and complex objects modelling is still challenging due to nature of the input datasets and requirements that they must meet, i.e. correct geometry and topology. Remondino (2003) gave an overview of the reconstruction algorithms and proposed their classification, dividing the processing from unorganized point clouds to the final surface into four major steps: pre-processing, topology determination, generation of the polygonal surface and post-processing.

\section{CASE STUDY}

In this section the complete process of 3D modelling is described, from survey planning, through data acquisition, surface reconstruction and post-processing, to final texturing and visualization. Even though the workflow is similar in both 
cases, each dataset required an individual treatment. In the photogrammetric workflow, image calibration and orientation is necessary after image acquisition, to create dense point clouds in a common coordinate system. In the laser scanning workflow point clouds must be registered into a common coordinate system (Fassi, 2007).

\subsection{Study area description}

In this study one of the most popular places in the Polish Tatra Mountains was chosen - surroundings of the Gassienicowa Valley and Orla Perć (legendary alpine tourist route). Differences in altitude reach $800 \mathrm{~m}$, landscape changes from sub-alpine dwarf pine shrubs, through alpine meadows right up to bare rocks. Broad valleys are surrounded by steep rock cliffs.

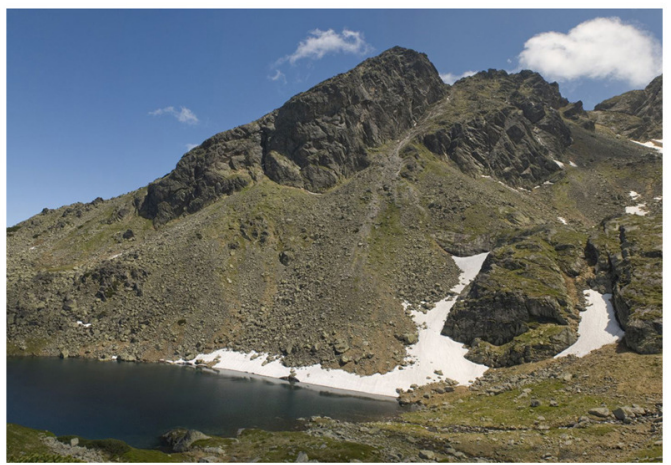

Figure 1. Study area - the western slopes of the Kościelec Mt.

Western walls of the Kościelec Mountain (2155 m) - the exact object of the investigation - is one of the most interesting and popular rock climbing areas in the Polish High Tatra Mts. The wall is about 300 meters high, has varied relief and some parts are overhung (Figure 1).

\subsection{Survey planning and data acquisition}

Terrestrial survey in mountainous region is demanding due to the diverse topography. Scan and photo locations were carefully chosen to ensure the best insight into the Kościelec walls. However, their complexity and irregularity did not allow to fully cover the site. Table 2 summarises the data acquisition. Figure 2 presents scanner and camera locations.

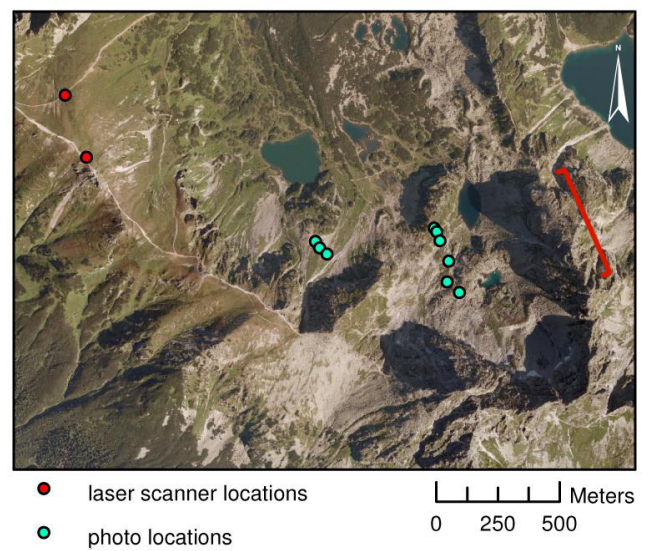

Figure 2. Scanner and camera locations in the upper part of the Gąsienicowa Valley. Kościelec ridge is marked with the red bracket

\begin{tabular}{|l|c|c|}
\hline Characteristic & photogrammetry & TLS \\
\hline Total points [mln] & 2.1 & 1.2 \\
Photos / Scans & 30 & 3 \\
Stations & 9 & 2 \\
Max distance [m] & 1150 & 2250 \\
Min distance [m] & 200 & 1650 \\
\hline
\end{tabular}

Table 2. Summary of data acquisition

Terrestrial photogrammetry: In 2010, about thirty images for the photo-based scanning were taken with SLR camera Nikon D80 equipped with 10 millions pixels CCD-matrix and 20 and $50 \mathrm{~mm}$ prime lenses. The camera was pre-calibrated to provide more accurate results. Pixel size varied from $0.07 \mathrm{~m}$ to $0.22 \mathrm{~m}$ due to lenses and object distance. Much higher portability allowed coming close to the slopes, but some potentially good locations occurred dangerous and remained inaccessible. The field work took about 5 hours and it could have been done by a single person.

Bundle adjustment and stereo matching was performed in Photomodeler Scanner software. Root mean square error of point marking was equal 0.504 pixels (maximum 1.181 pix, minimum 0.005 pix) and point tightness ranged from $0.001 \mathrm{~m}$ to $0.550 \mathrm{~m}$. Five dense point clouds were automatically created out of the image pairs having the best geometry. The clouds comprised 2.1 million points altogether, all in one common coordinate system. RGB value was automatically extracted from the photo giving the point cloud a textured appearance (Photomodeler, 2011).

Terrestrial laser scanning: Three laser scanning point clouds were acquired from two positions during the campaign in summer 2009 using the Riegl Laser Profile Measuring System LPM-321 (Riegl, 2011). The device was designed to be used in monitoring, topography, mining and archaeology. It allows ranging up to 6000 meters with nominal accuracy of $25 \mathrm{~mm} \pm$ $20 \mathrm{ppm}$ and field of view up to $150^{\circ}$ (vertically) by $360^{\circ}$ (horizontally). Even though integration with high-resolution digital camera is possible, it was not used during the survey.

Because of the weight of the scanner and other necessary equipment, scanning positions were chosen near to the cable railway station, which allows an easy access to the main ridge. The positions were rather distant from the study area, however Kościelec was within the reach of the LPM. The mean sampling distance was $20 \mathrm{~cm}$ for each scan, and the volume of raw point clouds was about 1.2 million points, each cloud in its local coordinate system. Nevertheless, they still contained some occlusions (holes) because of the topography. The field work took two days, for a surveying team made up of xx persons.

\subsection{Digital modelling and quality assessment}

Further processing of the two datasets was conducted in the trial version of Geomagic Studio 12 - the reverse engineering software. At the very beginning of data processing, blunders and gross errors were removed to avoid disturbances in alignment. The laser scanning point clouds were first manually roughly aligned, and then the best-fit method was used to automatically optimize the results. The photo-based and laser point clouds were merged into two datasets, respectively. Noisy points were identified and moved to the local average surface, to reduce some random deviations. To represent the true-3D surface with its complicated relief triangular mesh was chosen. The main obstacle in correct surface reconstruction was its great roughness and irregularity. The processing was therefore time 
consuming and demanded manual interaction and editing after automatic meshing. It was necessary to fill holes, remove tunnels, spikes, overlapping triangles, etc. The curvature priority enabled to decrease the number of polygons and to avoid simultaneous over-smoothing, because the areas with high degrees of curvature were ignored while the smoothing operation and edges were preserved.

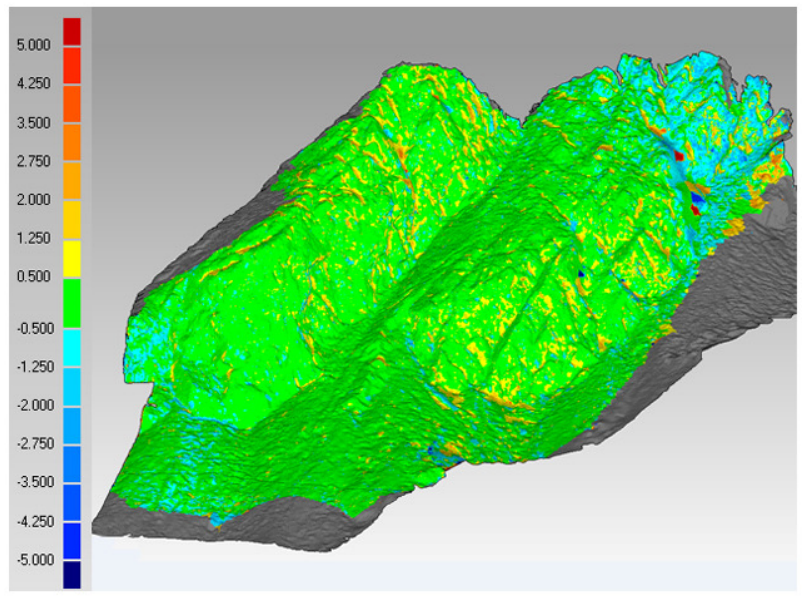

Figure 4. Relative comparison of photo-based and laser scanning-based models

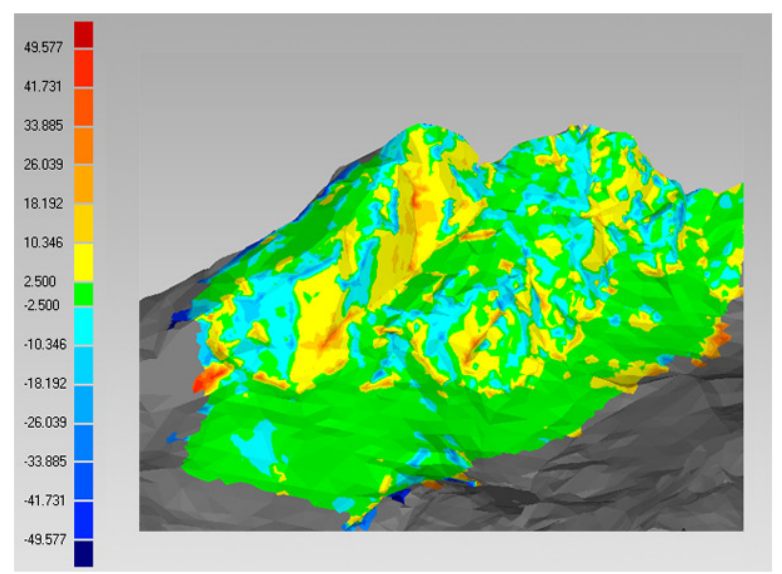

Figure 5. Comparison of laser scanning-based model and standard DTM

Photogrammetric and laser scanning models were aligned, and a distance between them was computed to assess relative accuracy of both datasets. The differences between 3D models occurred mainly in occluded areas that were filled automatically due to the lack of input points. Average distance between photogrammetric and laser scanning models was equal $0.25 \mathrm{~m} \pm$ $0.12 \mathrm{~m}$ (Figure 4).

Both 3D models were also compared to the standard DTM of the Tatra Mountains in TIN format, obtained from aerial photographs ( $0.22 \mathrm{~m}$ ground pixel size), showing deviations reaching up to $50 \mathrm{~m}$ in both cases (Figure 5). The largest deviations occur in the steepest parts of the wall, where the DEM has the lowest accuracy.

\subsection{Texturing and visualization}

Generally 3D models can be displayed in wireframe, shaded or textured mode, enabled by many available software packages. To achieve a more smooth result for visualization, NURBS curves and surfaces were utilized. Comparison of the input points and generated NURBS shows that the differences between them do not exceed $2 \mathrm{~mm}$. The photogrammetric model was textured directly from the input photographs. Two options to achieve this goal were tested: either RGB values of each vertex were interpolated to colour the triangles, or texture from suitable photograph was projected onto the mesh. The second option provided a better visual impression and that is why the surface was textured into Photomodeler Scanner software (Figure 6). As no camera was integrated with the laser scanner, the model was left textureless.

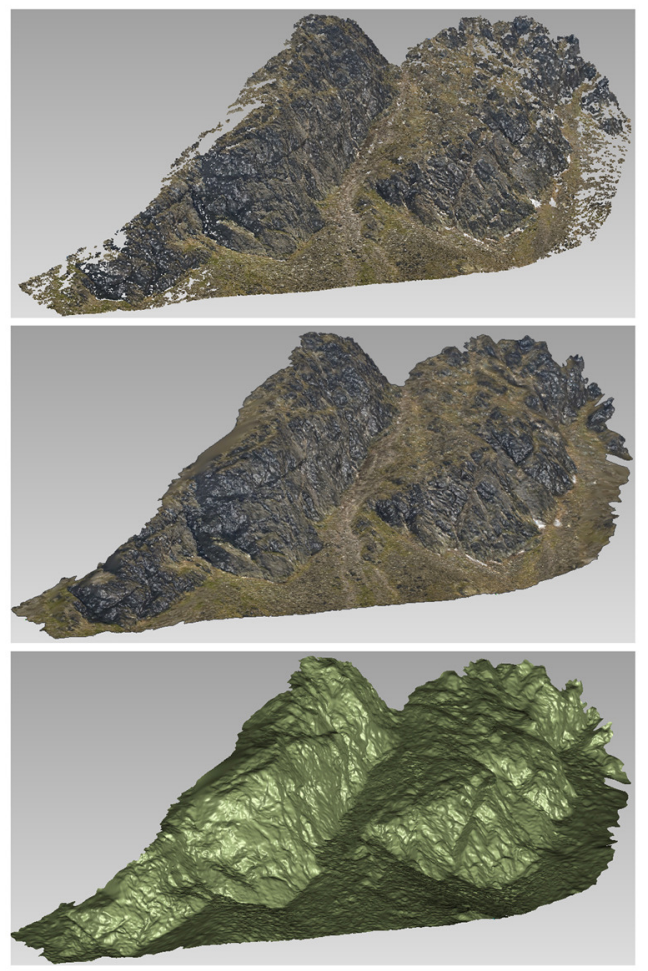

Figure 6. Kościelec walls visualized as an RGB point cloud, photo-textured mesh and NURBS surface

\section{CONCLUSIONS}

The question which measurement technique is better cannot be easily answered. Both methods have significant differences in an overall characteristics and data acquisition requirements. If only one technology to model mountain slopes should be chosen, photo-based techniques seemed more efficient, because:

1. cost of high-quality equipment is much lower,

2. equipment is easily portable and camera locations can be chosen more conveniently,

3. field work takes significantly less time, minimizing costs, risks and allowing immediate registration of the state of the object,

4. photographs provide colours useful for visualization,

5. problem with lack of textures rather does not apply to mountain slopes,

6. if using one of many commercial packages, design (sensor and network geometry), 3D measurements, structuring and modelling, texturing and visualization can be performed even by a non-specialist,

7. both methods give comparable results, concerning model accuracy and quality. 
However, TLS has also significant advantages:

1. one scanner location provides 3D data (in photogrammetry at least two locations are necessary),

2. laser beam can penetrate through vegetation,

3. point clouds are provided while field works (in photogrammetry it is obtained afterwards and can be time consuming).

Obviously the choice depends mainly on an object or area, project requirements, budget and time, equipment availability and user's previous experience.

\section{REFERENCES}

\section{References from Journals:}

Abellán, A., Vilaplana, J.M., and Martinez, J., 2006. Application of a long-range terrestrial laser scanner to a detailed rockfall study at Vall de Núria (Eastern Pyrenees, Spain). Engineering Geology, 88(3-4), pp. 136-148.

Bellian, J.A., Kerans, C., Jennette, D.C., 2005. Digital outcrop models: applications of terrestrial scanning lidar technology in stratigraphic modeling. Journal of Sedimentary Research, 75(2), pp. 166-176.

Buckley, S.J., Howell, J.A., Enge, H.D., Kurz, T.H., 2008. Terrestrial laser scanning in geology: data acquisition, processing and accuracy considerations. Journal of the Geological Society, London, 165(3), pp. 625-638.

Haneberg, W.C., 2008. Using close range terrestrial digital photogrammetry for 3-D rock slope modeling and discontinuity mapping in the United States. Bulletin of Engineering Geology and the Environment 67(4), pp. 457-469.

Lambers, K., Eisenbeiss, H., Sauerbier, M., Kupferschmidt, D., Gaisecker, Th., Sotoodeh, S., Hanusch, Th., 2007. Combining photogrammetry and laser scanning for the recording and modelling of the late intermediate period site of Pinchango Alto, Palpa, Peru. Journal of Archaeological Science, 34(10), pp. 1702-1712.

Lerma, J., Navarro, S., Cabrelles, M., Villaverde, V., 2009. Terrestrial laser scanning and close range photogrammetry for 3D archaeological documentation: the Upper Palaeolithic Cave of Parpalló as a case study. Journal of Archaeological Science, Volume 37, Issue 3, pp. 499-507.

Mikoš, M., Vidmar, A., Brilly, M., 2005. Using a laser measurement system for monitoring morphological changes on the Strug rock fall, Slovenia. Natural hazards and earth system sciences, 5, pp. 143-153.

Remondino, F., El-Hakim, S., 2006. Image-based 3D modelling: a review. Photogrammetric Record, 21(115), pp. 269-291.

Sturzenegger, M., Stead, D. 2009a. Close-range terrestrial digital photogrammetry and terrestrial laser scanning for discontinuity characterization on rock cuts. Engineering Geology, 106 (2009), pp. 163-182.

Sturzenegger, M., Stead, D. 2009b. Quantifying discontinuity orientation and persistence on high mountain rock slopes and large landslides using terrestrial remote sensing techniques. Natural Hazards and Earth System Sciences, 9, pp.267-287.
Wangensteen, B., Eiken, T., Odegard, R.S., Sollid, J.L., 2007. Measuring coastal cliff retreat in the Kongsfjorden area, Svalbard, using terrestrial photogrammetry. Polar Research, 26(1), pp. 14-21.

\section{References from Books:}

Kraus K., 2007. Photogrammetry. Geometry from Images and Laser Scans. Walter de Gruyter, Berlin.

Lerma García, J.L., Van Genechten, B., Heine, E., Santana Quintero M., 2008. 3D RiskMapping. Theory and practice on terrestrial laser scanning. Training material based on practical applications. Universidad Politécnica de Valencia, Valencia.

Luhmann, T., Robson, S., Kyle, S., Harley I., 2006. Close Range Photogrammetry: Principles, Techniques and Applications. Whiteless Publishing, Dunbeath.

Rosser, N.J., Dunning, S.A., Lim, M., Petley, D.N., 2007. Terrestrial laser scanning for quantitative rockfall hazard assessment. In: Hungr, O., Fell, R., Couture, R., Ebergardt, E. (eds) Landslide Risk Management. A.T. Balkema, Amsterdam.

\section{References from Other Literature:}

Beraldin J.A., 2004. Integration of Laser Scanning and CloseRange Photogrammetry - The Last Decade and Beyond. In: Proceedings of the XXth International Society of Photogrammetry and Remote Sensing (ISPRS) Congress, Istanbul, Turkey, July 12-23 (2004), pp. 972-983.

Birch, J.S., 2006. Using 3DM Analyst Mine Mapping Suite for Rock Face Characterisation. In: Tonon, F., Kottenstette J.T. (eds.) Laser and Photogrammetric Methods for Rock Face Characterization. Report on a workshop held June 17-18, 2006 in Golden, Colorado, pp. 13-32.

Buckley, S.J., Schwarz, E., Terlaky, V., Howell, J.A., Arnott, R.W.C., 2009. Terrestrial laser scanning combined with photogrammetry for digital outcrop modelling. In: International Archives of the Photogrammetry, Remote Sensing and Spatial Information Sciences, Vol. 38(B3), pp. 75-80.

Cabrelles, M., Seguí, A.E., Navarro, S., Galcerá, S., Portalés, C., Lerma, J.L., 2010. 3D Photorealistic modelling of stone monuments by dense image matching. In: International Archives of Photogrammetry, Remote Sensing and Spatial Information Sciences, Newcastle upon Tyne, UK, Vol. XXXVIII, Part 5, pp.121-124.

Campana, S., Remondino F., 2008. Fast and detailed digital documentation of archaeological excavations and heritage artifacts. Layers of perception. In: 35th Proceedings of the CAA conference, Bonn, pp. 36-42.

El-Hakim, S.F., Beraldin, J.A., Blais, F., 1995. A comparative evaluation of the performance of passive and active $3 \mathrm{D}$ vision systems. In: Proceedings of the SPIE Conference on digital photogrammetry, St. Petersburg, Russia, Vol. 2646, pp. 14-25.

Fassi, F., 2007. 3D modeling of complex architecture integrating different techniques - a critical overview. In: International Archives of Photogrammetry and Remote Sensing, Vol. XXXVI-5/W47, pp. 1-11.

Hsiao, K.H., Liu, J.K., Yu, M.F., Tseng Y.H., 2004. Change Detection of Landslide Terrains using Ground-based LIDAR 
Data. In: XXth ISPRS Congress, Istanbul, Turkey, Commission VII, WG VII/5, pp. 617-621.

Hoppe C., Krömker S., 2009. Adaptive meshing and detailreduction of 3D-point clouds from laser scans. In: Proceedings of ISPRS Workshop 3D ARCH 2009, Trento (Italy), February25-28.

Hullo, J.F., Grussenmeyer, P., Fares, S., 2009. Photogrammetry and Dense Stereo Matching Approach Applied to the Documentation of the Cultural Heritage Site of Kilwa (Saudi Arabia). In: Proceedings of 22nd CIPA Symposium, October 11-15, 2009, Kyoto, Japan, on CD Rom, 6 pp.

Jansa, J., Studnicka, N., Forkert, G., Haring, A., Kager, H., 2004. Terrestrial laserscanning and photogrammetry acquisition techniques complementing one another. In: Altan O. (ed) Proceedings of the XX ISPRS Congress, Istanbul, pp. 948-953.

Kadobayashi, R., Kochi, N., Otani, H., Furukawa, R., 2004. Comparison and evaluation of laser scanning and photogrammetry and their combined use for digital recording of cultural heritage. In: International Archives of the Photogrammetry, Remote Sensing and Spatial Information Sciences, 35(5), pp. 401-406.

Kajuutti, K., Pitkänen, T., Geist, T., Heiskanen, J., Pellikka, P., 2003. Comparison of terrestrial photographs and laser scanner in production of digital elevation models for glaciers. In: Proceedings of EGS-AGU-EUG Joint Assembly, 6-11 April 2003, Nice, France.

Koch, M., Kaehler M., 2009. Combining 3D Laser-Scanning and Close-Range Photogrammetry - an Approach to Exploit the Strength of Both Methods. In: Making History Interactive. Computer Applications and Quantitative Methods in Archeology Conference, Willimsburg, VA.

Poropat, G.V., 2006. Remote 3D Mapping Of Rock Mass Structure. In: Tonon, F., Kottenstette J.T. (eds.) Laser and Photogrammetric Methods for Rock Face Characterization. Report on a workshop held June 17-18, 2006 in Golden, Colorado, pp. 13-32.

Remondino, F., 2003. From point cloud to surface: the modelling and visualization problem. In: International Archives of Photogrammetry, Remote Sensing and Spatial Information Sciences, Tarasp-Vulpera, Switzerland, Vol. XXXIV-5/W10.

Remondino, F., Girardi, S., Gonzo, L., Rizzi, A., 2008. Multiresolution modeling of complex and detailed Cultural Heritage. In: Proceedings of 9th International Symposium on Virtual Reality, Archaeology and Cultural Heritage (VAST), Braga, Portugal, pp. 1-8.

Remondino, F., Guarnieri, A., Vettore, 2005. 3D Modeling of closerange objects: photogrammetry or laser scanning? In: Beraldin, El-Hakim, Gruen, Walton (eds) Proceedings of Videometrics VIII - SPIE-IS\&T Electronic Imaging, Vol. 5665, pp. 216-225.

Remondino, F., Menna, F., 2008. Image Based Surface Measurement for Close-Range Heritage Documentation, International Archives of the Photogrammetry, Remote Sensing and Spatial Information Sciences, Beijing, China, Vol. XXXVII. Part B5, pp. 199-206.
Remondino F., Rizzi A., 2009. Reality-Based 3D Documentation of World Heritage Sites: Methodologies, Problems and Examples. In: Proceedings of 22 nd CIPA Symposium, October 11-15 2009, Kyoto, Japan.

Rönnholm, P., Honkavaara, E., Litkey, P., Hyyppä, H., Hyyppä, J., 2007. Integration of Laser Scanning and Photogrammetry. In International Archives of the Photogrammetry, Remote Sensing and Spatial Information Sciences, Vol. 36(3), pp. 355362.

Roncella, R., Forlani, G., Remondino, F., 2005. Photogrammetry for geological applications: automatic retrieval of discontinuity orientation in rock slopes. In: Videometrics $I X$, electronic imaging, IS\&T/SPIE 17th annual symposium, pp 1727.

Salman, N., Yvinec, M., Merigot, Q., 2010. Feature Preserving Mesh Generation from 3D Point Clouds. In: Special issue for EUROGRAPHICS Symposium on Geometry Processing Computer Graphics Forum, 29 (2010), 1623-1632.

Sima, A., Buckley, S., Schneider, D., Howell, J., 2010. An improved workflow for image- and laser-based virtual geological outcrop modelling. In: International Archives of the Photogrammetry, Remote Sensing and Spatial Information Sciences, Vol. 3 (B3), pp. 115-119.

Strouth, A. and Eberhardt, E., 2006. The use of LiDAR to overcome rock slope hazard data collection challenges at Afternoon Creek, Washington. In: Tonon, F., Kottenstette J.T. (eds.) Laser and Photogrammetric Methods for Rock Face Characterization. Report on a workshop held June 17-18, 2006 in Golden, Colorado, pp. 109-120.

Whitworth, M. C. Z., Giles, D. P. and Anderson, I., 2006. Terrestrial laser scanning for applied geoscience and landslide studies in the urban environment. In: Culshaw, M.G., Reeve, H.J., Jefferson, I., Spink, T.W. (eds.) Engineering geology for tomorrow's cities. The Tenth IAEG Congress, Nottingham, United Kingdom, 6-10 September 2006, paper number 252, on CD.

\section{References from websites:}

Photomodeler, 2011. http://www.photomodeler.com/ (accessed 28 March 2011)

Riegl, 2011. http://www.riegl.com/nc/ (accessed 27 March 2011) 